\title{
Tendencias de investigación en memoria histórica y sus desafios pedagógicos en Latinoamérica
}

\section{Luisa Fernanda Ciro Solórzano}

https://orcid.org/0000-0002-0564-1769 Universidad del Ouindío, Colombia lfciros@uqvirtual.edu.co
Miguel Ángel Caro-Lopera

https://orcid.org/0000-0002-8940-2799 Universidad del Quindío, Colombia macaro@uniquindio.edu.co

\section{Resumen}

El presente artículo identifica las tendencias de las investigaciones en los procesos de construcción de memoria histórica desde el Estado, la sociedad civil y la escuela, y los desafios que se advierten en el sector educativo frente a este estado del arte. Este trabajo se ocupa de un corpus de 38 textos derivados de investigaciones durante el periodo posterior a las dictaduras en Chile (1990) y Argentina (1983) y de posconflicto en Colombia (2012). A partir de alli identifica como tendencias la intención del Estado por fomentar la construcción de memorias y de conferir a la escuela esa tarea. En cuanto a la sociedad civil, advierte el afán de consolidar espacios para resguardar las memorias y de asegurar resistencia frente a los agentes victimarios del pasado. En cuanto a la escuela, reconoce avances y esfuerzos pioneros en los tres nodos del sistema didáctico: profesor, estudiante y saber.

\section{Palabras clave (Fuente: tesauro de la Unesco)}

Conflictos armados; educación para la paz; investigación histórica; Latinoamérica; memoria colectiva; memoria histórica.

Recepción: 23/01/2020 | Envío a pares: 05/03/2020 | Aceptación por pares: 30/06/2020 | Aprobación: 26/08/2020 


\title{
Research Trends in Historical Memory and its Pedagogical Challenges in Latin America
}

\begin{abstract}
This article identifies research trends in the processes of creating historical memory from the state, civil society, and school, and the significant challenges of the educational sector regarding this conjunction. This paper deals with a corpus of 38 texts derived from research during the post-dictatorship period in Chile (1990) and Argenti$n a(1983)$ and the post-conflict period in Colombia (2012). Then, it identifies as trends the state's intention to promote the construction of memories and confer this task to school. As for civil society, it notes the effort to strengthen spaces for protecting memories and ensure resistance against past victimizing agents. Regarding school, it recognizes crucial breakthroughs in the three nodes of the teaching system: teacher, student, and knowledge.
\end{abstract}

\section{Keywords (Source: Unesco thesaurus)}

Historical research; peace education; armed conflicts; historical memory; collective memory; Latin America. 


\section{Tendências de pesquisa em memória histórica e seus desafios pedagógicos na América Latina}

\section{Resumo}

O presente artigo identifica as tendências das pesquisas nos processos de construção de memória histórica pelo Estado, pela Sociedade Civil e pela Escola, e os desafios que podem ser percebidos no setor educativo diante desse estado da arte. Este trabalho ocupa-se de um corpus de 38 textos derivados de pesquisas durante o período posterior às ditaduras no Chile (1990) e na Argentina (1983) e ao de pós-conflito na Colômbia (2012). A partir disso, identifica como tendências, a intenção do Estado de fomentar a construção de memórias e de dar à escola essa tarefa. Quanto à Sociedade Civil, observa-se a pressa em consolidar espaços para resguardar as memórias e de assegurar resistência em frente aos agentes vitimizadores do passado. Quanto à Escola, reconhece-se avanços e esforços pioneiros nos três nós do sistema didático: professor, estudante e saber.

\section{Palavras-chave (Fonte: tesauro da Unesco)}

Conflitos armados; educação para a paz; pesquisa histórica; América latina; memória coletiva; memória histórica. 
Este artículo de revisión, derivado de una tesis de maestría', busca examinar el estado del arte y elucidar prospectivas de cuanto queda por investigar en los procesos de enseñanza en la construcción de memoria histórica, desde las perspectivas del Estado, la sociedad civil y la escuela, en Argentina, Chile y Colombia, en períodos posteriores a la violencia y el conflicto. Sabemos muy bien de la función inestimable que cumplen los procesos de memoria histórica como factor de empoderamiento y de cohesión de los países, en aras de revisar críticamente los errores del pasado y de sopesar las fortalezas de su presente para proyectarse con conocimiento de causa hacia el futuro. En el ámbito colombiano, más allá de la creación de un centro de memoria o de la construcción de museos o de los procesos de terapia social que se adelanten con las comunidades afectadas, emerge la necesidad de concientizar al país sobre el valor de su memoria como hilo que lo cohesiona y lo catapulta al futuro. Un desafío de esta naturaleza es papel irrecusable de la escuela, pues en el trabajo con las nuevas generaciones se gestan las condiciones para una sociedad que erradique la violencia sistemática que ha agobiado al país. Así las cosas, construir memoria histórica sobre el pasado nos lleva a construir mejores futuros.

Esto se acentúa aún más en medio del estado de posconflicto en Colombia, como fenómeno sociopolítico aún convulso e incierto en el plano legal, pero, sin duda, abierto y retador -como aquí lo expresamos- para los gobiernos, las comunidades $y$, sobre todo, la escuela. En tal sentido, reconocemos -en sintonía con Jiménez et al. (2012) - que este terreno de investigación se muestra poco explorado en este país. En virtud de ello, partimos del estado del arte que proveen dichos autores, alrededor de

$1 \quad$ Se trata del trabajo de grado de Luisa Fernanda Ciro Solórzano La producción de crónicas en los procesos de construcción de Memoria Histórica. Propuesta didáctica interdisciplinar entre las ciencias sociales y el lenguaje (asesor Miguel Ángel Caro-Lopera, Maestría en Ciencias de la Educación, Universidad del Ouindío, 2019), inscrita en las líneas del grupo de investigación en Didáctica de la Lengua Materna y la Literatura (Dilema). las tres categorías desde las cuales compilan sus hallazgos y que podríamos denominar como: historia y narrativas a través de la oralidad (hasta 2000), memorias colectivas, entornos y comunidades (hasta 2005), memoria para la justicia y reparación (a partir del 2006).

De otro lado, nos anima el propósito de caldear la discusión en torno al papel de la escuela en la formación del pensamiento crítico, la ciudadanía, la promoción de los derechos humanos y la democracia, en el sentido de desfatalizar la memoria y pensar en lo que dejó -y aún deja- la guerra. Sabemos, como lo documentan las investigaciones, que la memoria se ha trabajado con las víctimas, en procesos adelantados en los territorios de intervención, pero somos conscientes de que dichos esfuerzos aún no alcanzan las metas esperadas, lo que propicia condiciones de intolerancia, discriminación y estigmatización proclives a la repetición y conservación del conflicto. A propósito, destacamos el informe emitido por el Centro Nacional de Memoria Histórica en el 2018, "Recorridos de la memoria histórica en la escuela: aportes de maestras y maestros en Colombia", en el cual se narran 16 experiencias de intervención en el aula, a través del trabajo de memoria históri$\mathrm{ca}$, liderado por docentes que conforman la Red Nacional de Maestras y Maestros por la Memoria y la Paz. Subrayamos de dicho estudio el hecho de que solo dos intervenciones de las allí descritas fueron realizadas en el aula regular, en zonas de mínima afectación, con población que no se considera víctima directa de los hechos tratados, lo que evidencia la desatención del sistema hacia gran parte de la población, hecho que retrasa el desarrollo y cumplimiento de las políticas nacionales que explicitan la obligatoriedad del trabajo de memoria histórica para la totalidad de los estudiantes.

Desde estas motivaciones adelantamos la presente revisión, que discurre entre 38 trabajos, compilados en tres categorías: Estado, sociedad civil y escuela. En cuanto a los procedimientos metodológicos que rigieron este rastreo documental, los crite- 
rios de selección de los textos fueron: 1) que se tratara de libros, capítulos, trabajos de grado o artículos en revistas académicas producto de investigación en Colombia, Argentina o Chile²; 2) que se ocuparan de períodos de posconflicto, por país de origen -en Chile, después de 1990; en Argentina, después de 1983, y en Colombia, después de 20123-; 3) que se movieran por los ámbitos educativo, histórico, sociológico o de análisis del discurso, en el marco de acciones pedagógicas. En el cumplimiento de estos criterios, procuramos garantizar el acceso directo a las fuentes, la exhaustividad, la actualidad y la historicidad de la revisión (Gómez et al., 2010, p. 78), al igual que la pertinencia, la pluralidad y la credibilidad (Cisneros y Olave, 2012, pp. 66-68). La Figura 1 resume este proceder metodológico.

Así las cosas, desglosaremos, en primer lugar, las tendencias comunes a los trabajos recogidos en las tres categorías asumidas y, posteriormente, esbozaremos algunos desafíos al papel de la escuela en dicho proceso, que despuntan en el horizonte investigativo.

\section{La memoria histórica en sus frentes de acción}

Tras establecer los criterios de búsqueda y limitar la revisión según los parámetros de interés, rastreamos tendencias conceptuales y metodológicas, además de puntos de encuentro entre los hallazgos y conclusiones de las investigaciones recolectadas. Cabe resaltar que las categorías elegidas -Estado, sociedad civil y escuela- no suponen compartimentos estancos; son, en el mejor de los sentidos, líneas porosas desde las cuales pretendemos acercarnos al

2 Con el fin de asegurar ciertos criterios de fiabilidad en cuanto al rigor de las investigaciones, acudimos solo a revistas indexadas por los sistemas de investigación avalados en cada país, a saber: la plataforma Scienti de Colciencias (Colombia), Scielo de Chile y Caicyt de Argentina.

3 Para los casos argentino y chileno, tenemos en cuenta el fin de los gobiernos militares; y para el caso colombiano, la ins tauración de la mesa de negociación con uno de los grupos armados: las Fuerzas Armadas Revolucionarias de Colombia - Ejército del Pueblo (FARC-EP). panorama investigativo de la memoria histórica en Colombia, Chile y Argentina. Abordaremos, en consecuencia, tales categorías a partir de sus rasgos generales y las tendencias de los trabajos que las integran.

\section{El Estado}

Como inicio a este abordaje triádico, miraremos el Estado en su función de mediador en los intereses de los grupos que lo conforman, no sin antes reconocer que su imagen en Latinoamérica se ha desdibujado en lo que tiene que ver con las intenciones políticas. En efecto, para Faletto (1993) la figura del Estado en los países latinoamericanos no es, como en el caso europeo, el resultado de un trasegar social que cristaliza el derecho a ejercer la individualidad, en el marco de lo colectivamente acordado, sino que se liga a la garantía de los derechos vistos en calidad de servicios (educación, salud, vivienda, etc.). En este sentido, los Estados latinoamericanos se saturan en sus funciones y descuidan su función orgánica de mediar entre los grupos sociales con autoridad y proyección de futuro. Así, observamos responsabilidad del Estado en las esferas política, económica y social, en la medida en que ha asumido deberes y problemáticas profundas, heredadas históricamente de modelos anteriores de sociedad. La equidad, la integración y el desarrollo social, el crecimiento económico y otras formas de bienestar colectivo se convierten en asuntos pendientes de los Estados latinoamericanos que desbordan su capacidad de acción.

Faletto ubica este fenómeno en una situación de "crecimiento desordenado" (1993, p. 28) que arrastra al Estado hacia la inmediatez y la necesidad de resolver lo urgente, desconociendo las posibilidades de futuro. En consecuencia, el afán del Estado por ocuparse del presente ha permitido evidenciar la adopción de sistemas de gobierno opresivos, algunos de ellos concretados en dictaduras. De esta manera, la inconformidad resultante en las sociedades por la presión apabullante y despojadora del Estado -y sus gobernantes- acrecienta las tensiones y da 
paso a graves conflictos internos. En Suramérica, a mediados del siglo pasado, los abusos del conflicto y la violencia se extendieron por cuenta del Estado. Países como Brasil, Argentina, Chile y Uruguay vivieron dictaduras militares que marcaron dichas sociedades por el ejercicio profundo de la violencia y la represión; en la misma línea, en Colombia y Perú, el conflicto interno entre el Estado y grupos subversivos puso a la sociedad civil en medio de profundos enfrentamientos y violaciones de los derechos humanos.
A propósito de esta dinámica entre el poder y la violencia, Figueroa (2001) hace un paralelo entre la legitimidad de la violencia del Estado democrático y el uso de la violencia en las dictaduras, con énfasis especial en los casos de nuestro continente. Según el autor, un punto de partida importante para la comprensión de la problemática de la violencia es la legitimidad que existe en su uso por parte del Estado. El ejercicio del poder a través de la monopolización de la violencia hace parte de la misma concepción del

Figura 1. Resumen de la metodología asumida

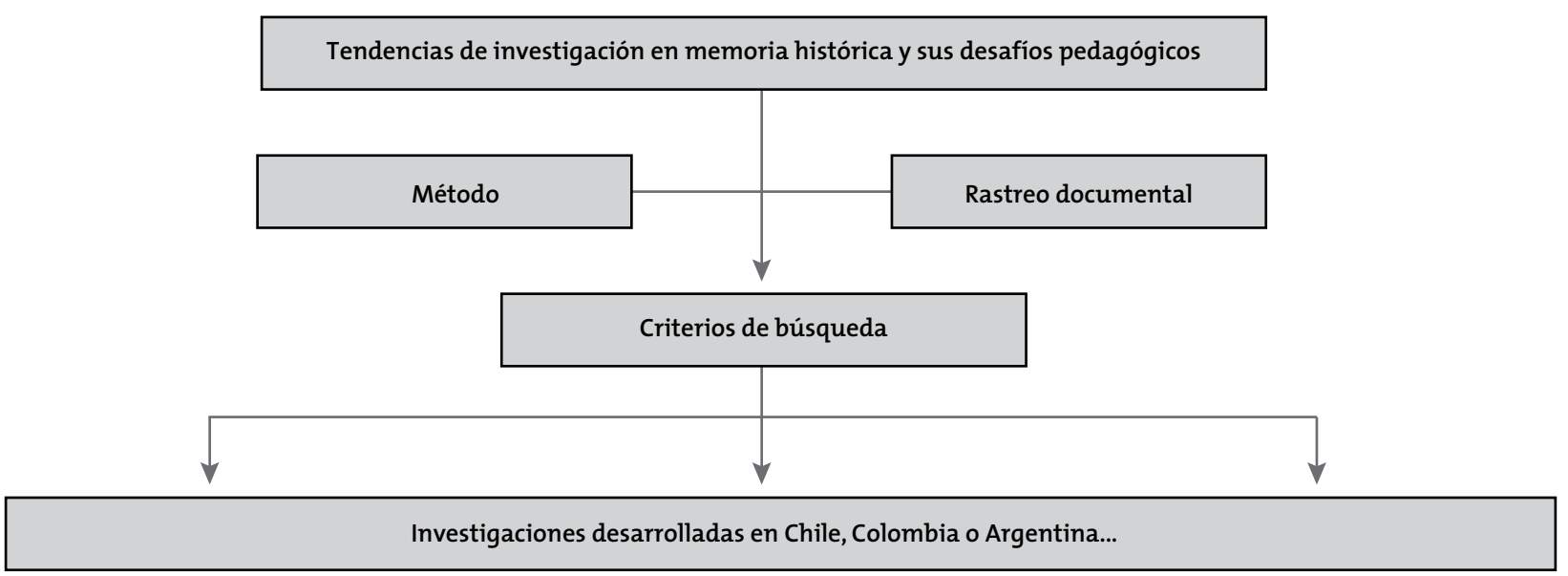
- lineamientos legales que direccionan el trabajo de memoria histórica desde el Estado...

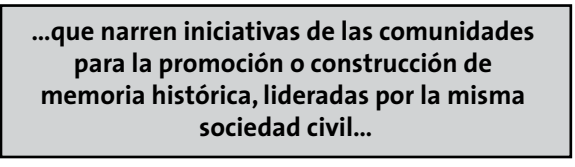

...que narren experiencias de enseñanzaaprendizaje sensibilización o promoción de memoria histórica en instituciones educativas...

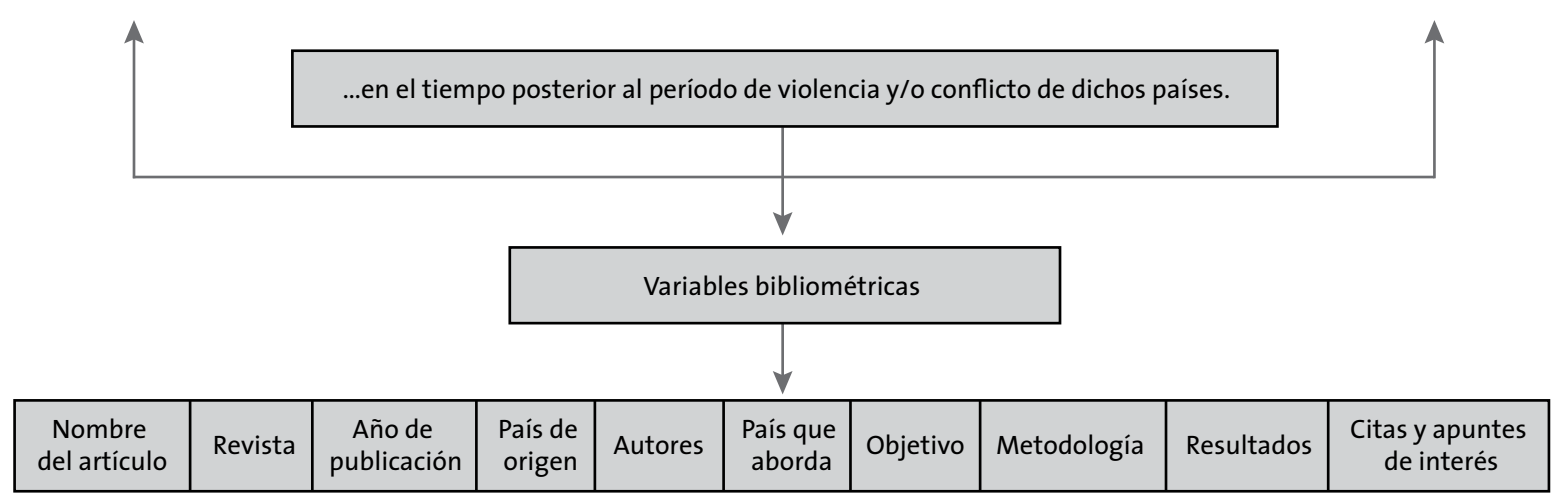

Fuente: elaboración propia. 
Estado. Sin embargo, la diferencia entre la violencia del Estado democrático y la de la dictadura se determina en la regulación legal de la misma. En el primer caso -el del Estado democrático- se restringe el uso de la fuerza para casos legislativamente extremos, mientras que para la dictadura la violencia es abiertamente aceptada y ejercida en la cotidianidad de la sociedad. Recordemos que los casos de instauración de dictaduras en Suramérica fueron justificados como medidas necesarias para la regulación del Estado. De otro lado, la violencia del Estado es proporcional a la resistencia de la sociedad, y la aceptación de las condiciones que ofrece el Estado a la sociedad civil determinan la dinámica violencia-poder, que varía según los casos. En este marco, el terror es garantía de respeto y estabilidad. La violencia sistemática es, para Figueroa, un efecto de inercia que nace en el presente y se aprovecha en el futuro; es decir, "si la amenaza del ejercicio de la violencia del Estado se hace realidad en el presente, en el futuro solo habrá que amenazar para aterrorizar. Los gobernados se amedrentarán y paralizarán sin que haya necesidad de matarlos o desaparecerlos" (2001, p. 42).

Precisamente, es el tratamiento de la memoria histórica de estos periodos de violencia, resultantes de los conflictos internos, el que rastreamos en este trabajo. Tomaremos, entonces, los casos de las dictaduras de Argentina y Chile y el caso de Colombia. En este orden de ideas, el criterio de búsqueda fue construido con el objetivo de conocer cómo interviene el Estado en una etapa posterior a la violencia y a través de qué medios garantiza el no olvido de las víctimas y las problemáticas. Propiamente buscamos investigaciones que abordaran las políticas o lineamientos legales y que, a su vez, orientaran el trabajo de memoria histórica desde el Estado, en el tiempo posterior al periodo de violencia y/o conflicto de dichos países.

Ahora bien, consideramos politicas de la memoria "las formas de gestionar o lidiar con ese pasado a través de medidas de justicia retroactiva, juicios histórico-políticos, instauración de conmemoraciones, fechas y lugares, o apropiaciones simbólicas de distinto tipo" (Rabotnikof, 2007, p. 261). Así las cosas, las políticas de la memoria histórica se refieren a la implementación o impacto de las acciones del Estado sobre los hechos y las víctimas existentes en cada país. Con base en dicha aclaración, el rastreo arrojó doce investigaciones que dividimos en dos grupos: cristalización de la memoria colectiva, y legislación y escuela (Tabla 1),

\section{Cristalización de la memoria colectiva}

El primer grupo podría ser nominado como cristalización de la memoria colectiva (Crenzel, 2008; Montero, 2008; Oteíza y Pinuer, 2010; Uprimny, 2011; Larralde, 2014; Villa y Barrera, 2017)4. Aquí observamos investigaciones que reflexionan acerca de la importancia del reconocimiento del Estado de los hechos violentos y que recogen diversas experiencias de adopción de políticas nacionales, análisis de discursos de gobernantes, estructuras e intenciones de informes y documentos referidos a la violencia estatal. Estos trabajos apuntan a la importancia de la promoción de la memoria colectiva e invitan a conocer las memorias oficiales y a contrastarlas con las memorias débiles, ejercicios inherentes a la justicia y la reparación. En consecuencia, abogan por tensar la memoria para construir la historia en vías democráticas; de lo contrario, las víctimas cargarían con

4 El trabajo de Crenzel (2008) analiza el informe Nunca Más, elaborado por la Comisión Nacional sobre la Desaparición de Personas (Conadep) en Argentina; el de Montero (2008) revisa las tensiones y complejidades inherentes a los procesos de construcción de memoria colectiva, a partir de un discurso presidencial argentino; el de Oteíza y Pinuer (2010) examina los informes oficiales sobre violaciones de los derechos humanos en Chile-Informe Rettig e Informe Valechy extrapola desde allí diversas conclusiones en torno a los procesos de reconstrucción de las memorias históricas; el de Uprimny (2011) analiza críticamente los alcances y limitaciones de la Ley de Víctimas en Colombia, a la luz del concepto de memoria; el de Larralde (2014) sigue el desarrollo de las políticas sobre la memoria en una ciudad argentina por un período de veinte años; y el de Villa y Barrera (2017) adelanta una revisión del estado de la cuestión sobre políticas de memoria en relación con la construcción de identidades nacionales en Colombia. 
Tabla 1. Investigaciones encontradas para la categoria de Estado

\begin{tabular}{|c|c|c|c|}
\hline \multicolumn{4}{|c|}{ Grupo 1: Cristalización de la memoria colectiva } \\
\hline AÑo & Autor(ES) & Título & País \\
\hline 2008 & Crenzel, E. & $\begin{array}{l}\text { El relato canónico de las desapariciones en Argentina: el informe } \\
\text { Nunca Más }\end{array}$ & Argentina \\
\hline 2008 & Montero, A. & $\begin{array}{l}\text { Justicia y decisión en el discurso presidencial argentino sobre la } \\
\text { memoria (2003-2007) }\end{array}$ & Argentina \\
\hline 2010 & Oteíza, T. y Pinuer, C. & $\begin{array}{l}\text { La temporalidad, recurso estratégico en documentos oficiales } \\
\text { de derechos humanos en Chile }\end{array}$ & Chile \\
\hline 2011 & Uprimny, C. & La memoria en la Ley de Víctimas en Colombia: derecho y deber & Colombia \\
\hline 2014 & Larralde, F. & $\begin{array}{l}\text { Políticas de la memoria. A propósito de su vigésimo aniversario } \\
\text { en la ciudad de La Plata (Argentina): la configuración de un } \\
\text { campo y sus prácticas }\end{array}$ & Argentina \\
\hline 2017 & Villa, J. D. y Barrera, D. & $\begin{array}{l}\text { Registro identitario de la memoria: políticas de la memoria e } \\
\text { identidad nacional }\end{array}$ & Colombia \\
\hline \multicolumn{4}{|c|}{ Grupo 2: Legislación y escuela } \\
\hline 2014 & Moreno, A. y Gamboa, R. & $\begin{array}{l}\text { Dictadura chilena y sistema escolar: "a otros dieron de verdad } \\
\text { esa cosa llamada educación" }\end{array}$ & Chile \\
\hline 2015 & Adamoli, M. et al. & $\begin{array}{l}\text { Educación y memoria. La historia de una política pública. } \\
\text { Historia de la educación }\end{array}$ & Argentina \\
\hline 2018 & Pagés, J. y Marolla, J. & $\begin{array}{l}\text { El papel de la memoria en la enseñanza de la historia en } \\
\text { América }\end{array}$ & $\begin{array}{l}\text { Argentina, Chile y } \\
\text { Colombia }\end{array}$ \\
\hline 2018 & Villalón, G. y Zamorano, A. & $\begin{array}{l}\text { Presencia y perspectivas de la enseñanza de la Historia reciente } \\
\text { en la Historia enseñada en la educación secundaria en Chile. Un } \\
\text { análisis desde el currículum }\end{array}$ & Chile \\
\hline 2018 & Díaz, M. y Rojas, N. & Educación para la ciudadanía en el posacuerdo & Colombia \\
\hline 2020 & Perochena, C. & $\begin{array}{l}\text { Entre el "deber de memoria" y el uso político del olvido: México } \\
\text { y Argentina frente al pasado reciente }\end{array}$ & Argentina \\
\hline
\end{tabular}

Fuente: elaboración propia.

el peso de no ser escuchadas, lo que dejaría brechas sociales de gran coyuntura, pues, en palabras de Traverso, "la Memoria de los oprimidos no deja de protestar contra el tiempo lineal de la historia" (2007, p. 39). Sobre lo anterior, Villa y Barrera sostienen que "la memoria colectiva deviene como acción política e ideológica y como escenario de disputa del poder para posicionar relatos y configurar subjetividades e identidades" (2017, p. 165). Asimismo, Uprimny postula la memoria como un derecho en dos dimensiones: individuales y colectivas, "siendo la memoria individual la encaminada a la reparación de la víctima y la colectiva la relativa a la memoria histórica, las garantías de no repetición y para la sociedad en general" (2010, p. 137). Para cerrar este grupo, podríamos decir que las investigaciones hallaron iniciativas estatales que reconocen la memoria como un derecho y que los tres países han adelantado esfuerzos legislativos para marcar líneas de acción con repercusión en la sociedad.

\section{Legislación y escuela}

Lo anterior nos lleva a un segundo grupo: legislación y escuela. Si bien este artículo más adelante se ocupará de detallar el ejercicio pedagógico y didáctico de la memoria histórica y su repercusión en el 
sistema educativo, este acápite dedicado a la legislación estatal se ocupa de describir las políticas de memoria dirigidas a la escuela. En el conjunto de investigaciones acerca de legislación y escuela (Moreno y Gamboa, 2014; Adamoli et al., 2015; Pagés y Marolla, 2018; Villalón y Zamorano, 2018; Díaz y Rojas, 2018; y Perochena, 2020 $)^{5}$ hallamos en común el contraste entre las propuestas curriculares concebidas por el Estado para el trabajo de la memoria histórica y la reflexión sobre ellas. Las investigaciones exploran diferentes escenarios y miradas sobre la inmersión del Estado en la escuela; no obstante, el trabajo de Pagés y Marolla (2018) representa un insumo importante por la comparación puntual de los currículos de Argentina, Chile y Colombia. Para estos autores, los tres países enuncian y mencionan el trabajo con memoria y la historia reciente, pero no socializan herramientas metodológicas ni didácticas al profesorado; por otro lado, los contenidos temáticos fomentan solo la descripción de acontecimientos del pasado, sin reflexión ni crítica. Así, "las propuestas que se entregan tienen más relación con la reconciliación que con la problematización de lo ocurrido en la historia reciente" (p. 178).

En suma, en cuanto al papel del Estado en los procesos de construcción de memoria histórica para Argentina, Chile y Colombia, las investigaciones encontradas, en un primer grupo, propenden por la necesidad de cristalizar la memoria colectiva, a par-

5 La investigación de Moreno y Gamboa (2014) describe la evolución de las políticas educativas en Chile desde el inicio de la dictadura militar hasta el período actual; la de Adamoli et al. (2015) describe la implementación de la política educativa del Estado argentino entre el 2005 y el 2015, en términos de la enseñanza del pasado reciente a las nuevas generaciones; la de Pagés y Marolla (2018) ofrece un estudio comparativo entre los currículos escolares de Argentina, Chile y Colombia en cuanto a la enseñanza de su historia reciente; la de Villalón y Zamorano (2018) se ocupa del análisis de los currículos vigentes sobre la enseñanza de la historia reciente en Chile; la de Díaz y Rojas (2018) establece relaciones entre la educación del posconflicto en Colombia y las experiencias de otros países en situación parecida; $y$ la de Perochena (2020) examina la memoria oficial del pasado violento y traumático en las presidencias de Cristina Fernández de Kirchner en Argentina (2007-2015) y de Felipe Calderón en México (2006-2012). tir del análisis de las políticas nacionales en torno a las responsabilidades estatales en medio de las violencias y los conflictos; y, en un segundo grupo, le toman el pulso a la manera como la legislación estatal estimula con políticas concretas el papel de la escuela en todos estos procesos de construcción de memoria histórica. Lo que falta por hacer en este panorama será fruto de un apartado posterior, una vez condensemos lo alcanzado por las investigaciones en los otros dos frentes.

\section{Sociedad civil}

En primer lugar, conviene desambiguar el concepto de sociedad civil y aterrizar la esencia de su significado en el campo de nuestro trabajo. Tomaremos como referencia el recorrido conceptual e histórico realizado por Pavón y Subucedo (2009), en el cual ponen en diálogo teórico las propuestas de Aristóteles, Hobbes y Locke y desde allí justifican el porqué de las agrupaciones humanas. Para Aristóteles, la sociedad civil o koinona politike es un acontecimiento natural por medio del cual el ser humano se hace humano en plenitud; en dicha premisa, un grupo se congrega para vivir en libertad y con solvencia política y económica 6 . Sin embargo, recuerdan los autores que lo anterior es debatido por Hobbes y Locke, quienes riñen con la idea de disposición natural a vivir en colectivo. Hobbes expone que las agrupaciones humanas, constituidas como sociedades civiles, nacen de la necesidad, es decir, son resultado de "un estado hecho, artificial o antinatural, producto de la necesidad, la disciplina y la voluntad" (Pavón y Subucedo, 2009, p. 67), una vinculación requerida a través de contratos sociales representados por leyes. La disposición antinatural a vivir en colectivo y acogerse a un régimen común como fuente de garantía para el bienestar de los grupos sociales es una idea compartida por Hobbes y Locke; sin embargo, estos

6 Según los apuntes de Pavón y Subucedo (2009: 65), la sociedad civil de Aristóteles era concebida a partir del ideal de lo que debía ser la polis actualmente: un asentamiento humano que contaba con autosuficiencia política y económica; esta concepción de polis está proyectada en el ideal de Estado. 
autores se distancian al definir el rol del gobernante: mientras que para Hobbes el gobernante es un estamento absoluto y se encuentra absuelto de las condiciones definidas por el contrato social que rige al colectivo, para Locke el gobernante es parte de este contrato y vive, al igual que el colectivo, en el marco de los acuerdos pactados. Podríamos sintetizar la reflexión de Pavón y Subucedo en un enunciado preciso: la multitud se vuelve ciudad cuando el individuo abandona el derecho de gobernarse y lo confia en el colectivo (2009, p. 68).

Con dichas aclaraciones, nuestro artículo asume la sociedad civil como el colectivo que se ordena y jerarquiza para restaurar los derechos desprovistos por acciones de violencia o negligencia del Estado. En armonía con lo dicho por Hobbes y Locke, recopilado por Pavón y Subucedo, los colectivos se tornan en sociedades civiles para obtener "la paz y la prosperidad: una paz y una prosperidad inherentes, en el caso de Locke, a la preservación de la sociedad y de sus miembros en el goce de las buenas cosas de esta vida que pertenecen a cada uno" (2009, p. 71; énfasis en el original). Para el caso de los periodos de violencia dados en Colombia, Chile y Argentina, las dinámicas políticas y sociales han atentado contra los derechos otorgados a un gran número de ciudadanos. $\mathrm{El}$ accionar violento que despoja al individuo de lo pactado en los contratos sociales de cada Estado -la legislación nacional- es el inicio de la conformación de colectivos que reclamen justicia y reparación.

En esta segunda parte orientamos la búsqueda hacia investigaciones que dieran cuenta de las iniciativas de las comunidades para la promoción o construcción de memoria histórica en el tiempo posterior al periodo de violencia y/o conflicto de los países de referencia. Los nueve trabajos reunidos confluyeron en dos grupos (la colectividad: un espacio para el luto y un resguardo de las memorias, y la memoria como resistencia), según la trascendencia política y pública alcanzada, es decir, el impacto social descrito en las mismas investigaciones (Tabla 2):

Tabla 2. Investigaciones encontradas para la categoria de sociedad civil

\begin{tabular}{|c|c|c|c|}
\hline \multicolumn{4}{|c|}{ Grupo 1: La colectividad: un espacio para el luto y un resguardo de las memorias } \\
\hline AÑo & AUTOR(ES) & Título & País \\
\hline 2013 & Cornejo, M. et al. & Historias de la dictadura militar chilena en las voces generacionales & Chile \\
\hline 2015 & Arenas, S. & $\begin{array}{l}\text { Luciérnagas de la memoria. Altares espontáneos y narrativas de luto en } \\
\text { Medellín, Colombia }\end{array}$ & Colombia \\
\hline 2016 & Castrillón, J. E. et al. & $\begin{array}{l}\text { Acciones colectivas como prácticas de memoria realizadas por una } \\
\text { organización de víctimas del conflicto armado en Medellín (Colombia) }\end{array}$ & Colombia \\
\hline 2018 & Raina, A. & $\begin{array}{l}\text { Sobre la necesaria vinculación entre historia y memoria en el estudio de la } \\
\text { historia reciente en Argentina. Reflexiones a partir de un análisis de caso }\end{array}$ & Argentina \\
\hline 2019 & Cueto, S. & $\begin{array}{l}\text { El origen de la Comisión Provincial por la Memoria de la provincia de } \\
\text { Buenos Aires (Argentina, 1999-2000) }\end{array}$ & Argentina \\
\hline 2020 & Torres, D. & $\begin{array}{l}\text { Museo de Memoria Histórica de Colombia (2012-2019): ¿Un lugar para el } \\
\text { diálogo memorial? }\end{array}$ & Colombia \\
\hline \multicolumn{4}{|c|}{ Grupo 2: La memoria como resistencia } \\
\hline 2010 & Cueto, S. & $\begin{array}{l}\text { Hijos de víctimas del terrorismo de Estado. Justicia, identidad y memoria } \\
\text { en el movimiento de derechos humanos en Argentina, 1995-2008 }\end{array}$ & Argentina \\
\hline 2017 & Rubio, G. y Osorio, J. & Memoria, Procesos Identitarios y pedagogías: el caso chileno & Chile \\
\hline 2018 & Ghilarducci, D. & $\begin{array}{l}\text { Víctimas y memoria histórica. Las madres de Plaza de Mayo y el } \\
\text { Movimiento de Víctimas de Crímenes de Estado en Colombia }\end{array}$ & $\begin{array}{l}\text { Argentina y } \\
\text { Colombia }\end{array}$ \\
\hline
\end{tabular}

Fuente: elaboración propia. 
La colectividad: un espacio para el luto y un resguardo de las memorias

El primer grupo podríamos denominarlo la colectividad: un espacio para el luto y un resguardo de las memorias (Cornejo et al., 2013; Arenas, 2015; Castrillón et al., 2016; Raina, 2018; Cueto, 2019; Torres, 2020)7. Se trata de investigaciones que caracterizan o reflexionan sobre grupos de víctimas que asumen la colectividad a manera de resguardo. En estos casos, se observa una resistencia pasiva para la garantía del no olvido; en palabras de Arenas: "formas de resistencia que no suponían un desafío al poder o a los poderes establecidos" (2015, p. 198). Aquí hallamos que las investigaciones describen cómo pervive la memoria en la cotidianidad, a través de redes de apoyo, monumentos discretos, convenciones sociales e imaginarios colectivos, con la intención de "visibilizar a los desaparecidos o muertos a través de las voces de familiares en los diferentes actos públicos", según lo precisan Castrillón et al. (2016, p. 415). De esta manera, se diversifican las voces que narran lo acontecido y confluyen en versiones que tensan la memoria oficial, sin transgredir o retar lo impuesto y sin representar una pauta para el cambio de lo establecido.

\section{La memoria como resistencia}

El segundo grupo, la memoria como resistencia, viene constituido por investigaciones que exploran las organizaciones que incursionan en la esfera pública de forma directa, abanderan su causa y asumen un papel político en procesos de justicia y reparación

$7 \quad$ El trabajo de Cornejo et al. (2013) ofrece un estudio cualitativo basado en historias de vida acerca de qué y cómo se recuerda la dictadura militar chilena; el de Arenas (2015) adelanta un estudio de caso sobre altares espontáneos y narrativas de luto en Medellín (Colombia); el de Castrillón et al. ( 2016) trabaja con personas pertenecientes a una organización de víctimas de la misma ciudad colombiana y aborda los significados y sentidos de las acciones de memoria colectiva; el de Raina (2018) explora críticamente la relación entre historia y memoria en el estudio de la historia reciente argentina; el de Cueto (2019) describe el proceso de creación y consolidación de la Comisión Provincial por la Memoria de la provincia de Buenos Aires; y el de Torres (2020) analiza el papel del Museo de Memoria Histórica de Colombia, como "lugar para el diálogo memorial".
(Cueto, 2010; Rubio y Osorio, 2017; Ghilarducci, 2018)8. Encontramos aquí trabajos que narran la experiencia y relevancia política de organizaciones que resisten y alcanzan la transformación en el entorno inmediato, marcan hitos referenciales y aportan a la reparación de víctimas. De este grupo, que conserva las características de fondo del primero -diversificar las voces en la narración de los hechos, visibilizar a las víctimas y tensar la memoria oficial-, cabe resaltar la diferencia en la transcendencia de sus acciones en el plano jurídico y social. Desde esta postura, Ghilarducci (2018), afirma que la incidencia de los grupos de víctimas se puede apreciar en dos frentes: uno nacional, que impacta las políticas que orientan las acciones de cada país, y otro internacional, por el papel en la redefinición del derecho internacional, que posiciona a estos actores como actores globales.

En resumen, las investigaciones que se ocupan de las formas como la sociedad civil asume los procesos de construcción de memoria toman dos rumbos: el primero, con un interés comprensivo que configura espacios que recojan el sentido de las pérdidas y perpetúen la memoria, de tal modo que las generaciones venideras no vayan a olvidar los episodios de dolor causados por la violencia; y el segundo, con un interés transformador/emancipatorio que busca, desde la praxis, que las comunidades -conscientes, autogestionadoras y empoderadas- garanticen que ese pasado ominoso no se repita.

\section{Escuela}

Para este tercer frente, desde el cual rastreamos las investigaciones sobre experiencias de memoria histórica, contamos con el antecedente declarado en el primer apartado sobre el Estado y sus

8 La investigación de Cueto (2010) gira en torno a la agrupación Hijos, organismo de derechos humanos conformado por hijos de víctimas del terrorismo del estado argentino; la de Rubio y Osorio (2017) aborda el tema de la "pedagogía de la memoria" que se desarrolla desde las organizaciones de víctimas de la violencia política en Chile; y la de Ghilarducci (2018) adelanta una comparación diacrónica entre el grupo de las Madres de Plaza de Mayo en Argentina entre 1977 y 1980 y el Movimiento de Víctimas de Crímenes de Estado en Colombia entre 2005 y 2008. 
lineamientos y orientaciones legales para los procesos formativos al respecto; sin embargo, el cómo se asumen estas directrices en la realidad pedagógica es el propósito concreto de las investigaciones que agrupamos en esta categoría. Se trata de trabajos que narran experiencias de enseñanza y aprendizaje, sensibilización o promoción de memoria histórica en instituciones educativas a lo largo de períodos posteriores a la violencia y/o conflicto de los países de referencia. No obstante, antes de detenernos en los rasgos identitarios de tales investigaciones, conviene hacer cierta antesala conceptual al análisis descriptivo de los resultados.

Inicialmente, entendemos que las investigaciones que piensan el rol de la escuela en el posconflicto dialogan con la idea de procesos democráticos escolares, democratización del aula, escuelas democráticas, en cuanto términos y discursos que sugieren la inserción de la democracia, en su sentido amplio, en la formación de las generaciones posteriores al conflicto. De hecho, Sierra y Medina (2012) asumen esta tarea como un reto al cual se deben sumar padres de familia y profesores para apalancar los procesos de interacción y comunicación de la comunidad educativa, y así construir una unidad común de sujetos sociales que se reconozcan como escuela. A su vez, sostienen que esta escuela -posible y necesaria- debe partir de "prácticas democráticas, participativas e incluyentes, como insumos esenciales para la construcción de nación, donde cada actor escolar sea reconocido como sujeto de derechos y objeto de deberes" (2012, p. 153).

En este mismo sentido, Domínguez y Feito reflexionan sobre el concepto de democracia, asumida como "una aspiración, un proyecto abierto, un proceso, una realidad en construcción, un viaje exploratorio inacabado" (2007, p. 14), que debe proyectarse en todos los ámbitos de la política, de la sociedad civil y del sistema productivo con una convicción sólida de libertad, igualdad, justicia, participación y autogobierno. Sin embargo, la tesis de los autores se desplaza hacia la formación de los ciudadanos que harán posible esa democracia. De esta manera aterrizamos en el concepto que nos ocupa de educación democrática, entendida como formación encaminada a la construcción de ciudadanía crítica, ética, política, intelectual e intercultural. Para el efecto, Domínguez y Feito (2007) elaboran tres indicadores que permiten interpretar las condiciones necesarias para democratizar un Estado o un sistema político, empresarial, institucional o educativo. Enunciados de forma sucinta, tales indicadores son: a) fines y objetivos democráticos que "pretenden satisfacer las necesidades, las aspiraciones, los deseos y los intereses objetivos, tanto individuales como colectivos"; b) configuraciones didácticas de acuerdo con principios democráticos, respeto a la soberanía, igualdad de derechos entre todos los sujetos, reconocimiento y aceptación de la diversidad, con especial prioridad a la participación; y c) fomento de las prácticas y procedimientos democráticos de diálogo, resolución de conflictos, cooperación, participación, autogestión (2007, p. 14). En cuestiones de este orden encontramos, de la misma manera, recurrentes menciones a la relación entre memoria y democracia y a la dinámica simbiótica de ambas en términos de reconocimiento, igualdad y participación de los actores y sus memorias individuales y colectivas.

Estas consideraciones ocupan, de algún modo, el trasfondo de las investigaciones que aquí recogemos, enfocadas en la intención detrás de las acciones mejoradoras o desde la perspectiva crítica al actual sistema. Díaz y Rojas, por ejemplo, afirman, para el caso colombiano, que "el desarrollo democrático de la escuela careció de fundamentación teórica y continuó con prácticas memorísticas en conceptos como participación, poder, democracia, entre otros, [lo que] omite la praxis de procesos participativos" (2018, p. 23). Esto limita, sin lugar a dudas, el accionar de la memoria, por la incipiente vida democrática escolar.

Así, el corpus recogido en torno a la categoría de escuela suma 17 investigaciones que podríamos clasificar en tres grupos el papel del docente, el impacto en los estudiantes y el saber que conlleva la memoria (Tabla 3): 
Tabla 3. Investigaciones encontradas para la categoria de Escuela

\begin{tabular}{|c|c|c|c|}
\hline \multicolumn{4}{|c|}{ Grupo 1: El papel del docente } \\
\hline AÑo & AUtOR(ES) & Título & Pais \\
\hline 2011 & González, M. & $\begin{array}{l}\text { Saberes y prácticas docentes en historia: usos y lecturas del } \\
\text { nunca más }\end{array}$ & Argentina \\
\hline 2013 & Toledo, M. y Magendzo, A. & $\begin{array}{l}\text { Golpe de Estado y dictadura militar: estudio de un caso único de } \\
\text { la enseñanza de un tema controversial en un sexto año básico de } \\
\text { un colegio privado de la región metropolitana, Santiago, Chile }\end{array}$ & Chile \\
\hline 2013 & Rivera, P. y Mondaca, C. & $\begin{array}{l}\text { El aporte de la enseñanza de la historia reciente en Chile: disensos } \\
\text { y consensos desde la transición política al siglo XXI }\end{array}$ & Chile \\
\hline 2015 & Bertola, C. et al. & $\begin{array}{l}\text { Entre el pensar, el decir y el hacer... Representaciones de los } \\
\text { docentes de ciencias sociales sobre el pasado reciente y su } \\
\text { posibilidad didáctica en el segundo ciclo del nivel primario }\end{array}$ & Argentina \\
\hline \multicolumn{4}{|c|}{ Grupo 2: El impacto en los estudiantes } \\
\hline 2004 & Raggio, S. & $\begin{array}{l}\text { La enseñanza del pasado reciente. Hacer memoria y escribir la } \\
\text { historia en el aula }\end{array}$ & Argentina \\
\hline 2015 & Londoño, J. y Carvajal, J. & $\begin{array}{l}\text { Pedagogías para la memoria histórica: reflexiones y } \\
\text { consideraciones para un proceso de innovación en el aula }\end{array}$ & Colombia \\
\hline 2015 & Torres, I. y Amaya, A. & $\begin{array}{l}\text { Construcciones y diálogos desde la enseñanza de la Historia } \\
\text { Presente y las Pedagogías de la Memoria en el escenario colombiano }\end{array}$ & Colombia \\
\hline 2016 & Torres, D. & $\begin{array}{l}\text { Museo de Memoria Histórica de Colombia (2012-2019): ¿Un lugar } \\
\text { para el diálogo memorial? }\end{array}$ & Colombia \\
\hline 2017 & González, F. y Gárate, C. & $\begin{array}{l}\text { El aprendizaje histórico en la educación secundaria. Jóvenes } \\
\text { chilenos y conciencia histórica }\end{array}$ & Chile \\
\hline \multicolumn{4}{|c|}{ Grupo 3: El saber que conlleva la memoria } \\
\hline 2009 & Magendzo, A. y Toledo, M. & $\begin{array}{l}\text { Educación en derechos humanos: currículum, historia y ciencias } \\
\text { sociales del } 2 \text { año de enseñanza media. Subunidad "Régimen } \\
\text { militar y transición a la democracia" }\end{array}$ & Chile \\
\hline 2012 & González, M. & $\begin{array}{l}\text { Historia y memoria del pasado reciente en la escuela: una mirada } \\
\text { a la propuesta oficial }\end{array}$ & Argentina \\
\hline 2016 & Padilla, A. y Bermúdez, A. & $\begin{array}{l}\text { Normalizar el conflicto y desnormalizar la violencia: retos y } \\
\text { posibilidades de la enseñanza crítica de la historia del conflicto } \\
\text { armado colombiano }\end{array}$ & Colombia \\
\hline 2016 & Rubio, G. & $\begin{array}{l}\text { Memoria hegemónica y memoria social. Tensiones y desafios } \\
\text { pedagógicos en torno al pasado reciente en Chile }\end{array}$ & Chile \\
\hline 2017 & Caturelli, M. & $\begin{array}{l}\text { Formar para la democracia en el nivel primario. Aportes desde } \\
\text { una experiencia en investigación }\end{array}$ & Argentina \\
\hline 2017 & Méndez, L. & $\begin{array}{l}\text { Desandando pasados, tejiendo futuros. Las ciencias sociales } \\
\text { escolares en perspectiva }\end{array}$ & Argentina \\
\hline 2018 & Mardones, R. & $\begin{array}{l}\text { Educación cívica y construcción de ciudadanía en el Chile de la } \\
\text { posdictadura, ¿en qué estamos y para dónde vamos? }\end{array}$ & Chile \\
\hline 2019 & González, F. y García, N. & $\begin{array}{l}\text { El aprendizaje histórico en la educación secundaria. Jóvenes } \\
\text { chilenos y conciencia histórica }\end{array}$ & Chile \\
\hline
\end{tabular}

Fuente: elaboración propia. 


\section{El papel del docente}

Las investigaciones del primer grupo (González, 2011; Toledo y Magendzo, 2013; Rivera y Mondaca, 2013; Bertola et al., 2015) $)^{9}$ ubican la labor del docente entre las tensiones propias de lo público y lo privado, de lo oficial y lo personal, de la historia colectiva y las vivencias particulares, de las versiones dominantes y las creencias personales; se trata, de acuerdo con el título propuesto por Bertola et al. (2015), de un dilema aún no resuelto, de un juego de permanentes oscilaciones entre el hablar y el callar, o de un ir y venir entre el pensar, el deciry el hacer.

\section{El impacto en los estudiantes}

Los trabajos del segundo grupo (Raggio, 2004; Londoño y Carvajal, 2015; Torres y Amaya, 2015; Torres, 2016; González y Gárate, 2017) $)^{10}$ analizan los efectos de la educación para la memoria histórica en los estudiantes. Estas investigaciones se mueven entre

9 El trabajo de González (2011) aborda los saberes y prácticas docentes de secundaria en relación con la última dictadura argentina; el de Toledo y Magendzo (2013) analiza un estudio de caso en torno a la enseñanza del golpe de Estado y dictadura militar chilena en sexto año básico de un colegio privado el de Rivera y Mondaca (2013) propone estrategias educativas para la enseñanza de la historia correspondiente al período político de la transición a la democracia en Chile; y el de Bertola et al. (2015) analiza las representaciones de docentes de ciencias sociales que trabajaban en el segundo ciclo de nivel primario alrededor del pasado reciente argentino.

10 La investigación de Raggio (2004) reflexiona sobre la enseñanza del pasado reciente en Argentina desde la perspectiva del estudiante; la de Londoño y Carvajal (2015) enfoca sus aportes en posibles procesos de innovación en el aula que hagan viable el proyecto de pedagogías para la memoria en el marco de un posconflicto en Colombia; la de Torres y Amaya (2015) examina la adopción de la memoria como objeto historiográfico en el panorama de la educación colombiana, a la luz de una revisión bibliográfica que identifica "puntos de conexión entre la enseñanza de la historia del tiempo presente y las elaboraciones de memoria en espacios escolares y no-escolares" (p. 382); la de Torres (2016) reflexiona, desde la revisión bibliográfica, sobre los conceptos de memoria, historia y conflicto, de acuerdo con los requerimientos del sistema educativo colombiano ante el reto del marco transicional para la paz; y la de González y Gárate (2017) adelanta un estudio exploratorio en cinco escuelas de Santiago de Chile sobre las valoraciones que otorgan los jóvenes al estudio de la historia, en contraste con las prácticas y formas de aprendizaje tradicionales que priman en el aparato educativo. paradojas parecidas a las del grupo anterior: de un lado, está la valoración positiva que hacen los jóvenes del aprendizaje de la historia, pero del otro permanecen los modelos de aprendizaje tradicionales que inhiben dichos procesos; de una parte, las intenciones de un aparato educativo proclive a la construcción de procesos de memoria histórica y, de la otra, el desencanto por los bajos resultados conseguidos entre los estudiantes. En medio de tales tensiones, que deben resolverse a favor de un impacto positivo en los estudiantes, están los maestros como sujetos pedagógicos, quienes -según Torres- materializan las políticas educativas y los proyectos institucionales (2016, p. 183), o quienes -según Torres y Amaya- deben gozar de "la voluntad, decisión, disposición, apertura y flexibilidad para emprender modificaciones, reacomodaciones y reestructuraciones institucionales al interior de los escenarios y programas en los cuales se lleva a cabo la labor educativa cotidiana" (2015, p. 401).

\section{El saber que conlleva la memoria}

Por último, los proyectos del tercer grupo (Magendzo y Toledo, 2009; González, 2012; Padilla y Bermúdez, 2016; Rubio, 2016; Caturelli, 2017; Méndez, 2017; Mardones, 2018; González y García, 2019)"1 giran

11 El trabajo de Magendzo y Toledo (2009) evalúa la educación en Derechos Humanos incluida en el currículum de historia y ciencias sociales del 2 año de Enseñanza Media en Chile; el de González (2012) transita por ámbitos de corte curricular en términos del análisis de la política educativa argentina en cuanto a la enseñanza de la historia reciente en la escuela; el de Padilla y Bermúdez (2016) formula recomendaciones para la enseñanza crítica de la historia del conflicto armado colombiano, a la luz de la apuesta por normalizar el conflicto y des-normalizar la violencia; el de Rubio (2016) analiza las narrativas de memoria sobre la historia reciente en el currículo chileno; el de Caturelli (2017), en Argentina, centra sus preocupaciones en la reconstrucción de sentidos respecto del concepto de democracia escolar, "a fin de establecer relaciones entre teorías pedagógicas y las prácticas escolares que genuinamente acontecen, en contextos singulares" (p. 173); el de Méndez (2017), en el mismo país, formula sugerencias didácticas, a partir de conceptos claves del universo social, como el espacio social, la, temporalidad y las identidades; el de Mardones (2018) explora el panorama de la educación cívica y construcción de ciudadanía en Chile durante su reciente época de posdictadura; y el de 
en torno a la construcción de los saberes escolares que supone la memoria histórica. Estos trabajos mantienen las alarmas frente a todo lo que la escuela tiene por hacer en este ámbito: desde la superación de las condiciones de desigualdad que sigue reproduciendo (Mardones, 2018) hasta la defensa de las prácticas escolares como "prácticas de ciudadanía democrática" (Caturelli, 2017, p. 179), sin olvidar, eso sí, el clamor por la recuperación del amor y la pasión a la hora de interactuar con los alumnos en el aula de clase (Méndez, 2017).

En síntesis, el balance de esta categoría deja más retos que logros, más tareas pendientes que avances. Sin embargo, podemos resaltar valiosos aportes en cada uno de los tres grupos que conforman esta categoría. Para el primero, el rescate de la esencia del ser maestro como sujeto ético y político; para el segundo, la necesidad de repensar el trabajo en el aula en función de provocar efectos positivos en el estudiante; y para el tercero, la reflexión sistemática en torno a los elementos claves de la memoria, la historia y el conflicto para configurar las nuevas apuestas didácticas de cara a los imperativos sociohistóricos de las posdictaduras y el posconflicto. Bien podemos colegir, en primer lugar, que cada uno de estos grupos gira en torno a los tres nodos del sistema didáctico -según Chevallard (1997): profesor, estudiante y saber enseñado y, en última instancia, a los elementos claves del sistema retórico (Meyer, 2013): al ethos (desde la reflexión crítica sobre la razón del ser maestro), al pathos (desde la necesidad de pensar en los intereses, afectos, saberes y expectativas del estudiante) y al logos (desde el diálogo de saberes entre el sujeto, sus espacios y sus tiempos), respectivamente. Todo esto nos permite elucidar una plataforma conceptual consistente desde la cual es posible proyectar pedagogías de la memoria histórica (Londoño y Carvajal, 2015; Torres y Amaya, 2015) que aboguen por una educación

González y García (2019) analiza, a la luz de la práctica escolar, el papel del arte y la literatura en la construcción de la memoria histórica. para la democracia (Caturelli, 2017) y la construcción de ciudadanía (Mardonés, 2018), desandando pasados y tejiendo futuros (Méndez, 2017), en el afán de alcanzar una conciencia histórica (Torres, 2016; González y Gárate, 2017) que nos permita normalizar el conflicto y desnormalizar la violencia (Padilla y Bermúdez, 2016).

\section{Algunos desafíos de investigación}

Luego de haber identificadolas tendencias más recurrentes en las tres categorías rastreadas, aventuramos aquí algunas tentativas de investigación que emergen de los trabajos mismos. Sin embargo, ante las múltiples ramificaciones que este intento podría generar y apoyados en los aportes esclarecedores que ya han formulado revisiones precedentes $^{12}$, preferimos centrarnos en las proyecciones que ofrece la investigación en el ámbito educativo. Al fin y al cabo, como lo aseveran Adamoli et al., "la escuela es la institución que asume con mayor responsabilidad la transmisión de ese pasado y la construcción de la memoria colectiva" (2015, p. 225). De hecho, sin menoscabar el valor de las investigaciones desde el Estado y la sociedad civil, la escuela concita la atención de las más preciadas transformaciones, pues se erige como el lugar por excelencia del diálogo entre generaciones: de aquella mayor que confía al maestro la interlocución en su nombre, y de aquella que se levanta, constituida por los estudiantes de los diferentes niveles educativos. No en vano se pregunta Mardones (a lo que responde, de inmediato, de forma negativa):

[...] ¿es posible cuestionar la calidad del ciudadano chileno, sus aptitudes si el sistema educativo no ha sido lo suficientemente efectivo en su preparación y formación? ¿Podríamos recriminar al ciudadano por su pasividad, por su prefe-

12 Larralde (2013) y Méndez (2017) en Argentina; Moreno y Gamboa (2014); Mardones (2018) y Villalón y Zamorano (2018) en Chile; Torres y Amaya (2015), Villa y Barrera (2017) y Díaz y Rojas (2018) en Colombia; y Pagés y Marolla (2018) en los tres países. 
rencia por el orden y la política institucionalizada si es eso lo que se le ha inculcado? (2018, p.80)

Acotado este campo de investigación, convenimos en sintetizar las prospectivas que advertimos en el marco del sistema didáctico (Chevallard, 1997), pues, a partir las dinámicas de interacción de los nodos de profesor, estudiante y saber se pueden gestar las innovaciones que en el aula reclaman los procesos de enseñanza y de aprendizaje de la memoria histórica.

\section{Desafios en cuanto al profesor}

En lo que respecta al profesor, los desafíos investigativos siempre serán elevados, pues al analizar su ethos emergen fundamentalmente dos problemáticas: la primera tiene que ver con la imposibilidad de que su actuación en el aula se ajuste a roles esperados y claramente distintos de los que podrían prescribir las didácticas de otras disciplinas; en efecto, para el caso de los procesos de construcción de memoria histórica, el perfil del maestro no puede ceñirse a los cánones de la objetividad o la neutralidad; como lo advierten Magendzo y Toledo, ocurre todo lo contrario:

Pedir a los docentes "neutralidad" y "objetividad" frente a lo acontecido es muy complejo y casi imposible. No se debe olvidar que pedagógicamente la enseñanza de los Derechos Humanos exige problematizar la realidad, confrontar ideas, dialogar en la aceptación de opiniones divergentes, establecer relaciones horizontales entre docentes y estudiantes, esclarecimiento del poder que conllevan las relaciones humanas y confrontación de los conflictos. (2009, p. 149)

La segunda problemática despunta de un imperativo irrebatible: el rol de transformación y emancipación al que está llamado el maestro, tal como lo apuntan Rivera y Mondaca:

En la actualidad educativa que vivimos, debemos reinventar las estrategias para el rescate del sujeto y postular nuevas formas de rearticular el tejido social, no solo en su gestación, sino que también en su dirección. Para ello es de vital importancia el rol docente, a través del curriculum oculto que oralmente trasmitimos y que debe ser inspirado por un compromiso social que recupere el papel de sujeto reflexivo y transformador de la Historia, activando la pereza e incluso el miedo de la Comodidad Neutra (el Pacifismo social), que aparece en muchos docentes al abordar metodológicamente el estudio de la historia reciente desde la óptica descriptiva y minimamente interpretativa. Es preciso entregar el paso a la innovación pedagógica y superar la comodidad neutra mediante la socialización de la propuesta, sus resultados y logros. (2013, pp.399-400)

De ahí que despunte el desafío de pasar de metodologías de corte contemplativo a otras de talante transformador; de investigaciones signadas por un interés comprensivo a otras de afán emancipador; de trabajos inspirados en las revisiones documentales a otros gestados en la intervención del aula; así, de la interpretación a la acción, del escritorio al aula, de la hermeneusis a la praxis, la investigación sobre las pedagogías de las memorias se prepara para dar el salto esperado, gracias a la intervención de su principal actor, el maestro, quien sigue el ejemplo de trabajos pioneros en Argentina, como los de González (2011), Bertola et al. (2015) y Caturelli (2017).

\section{DESAFÍOS EN CUANTO AL ESTUDIANTE}

En lo que respecta al estudiante, la investigación de González y Gárate (2017) ya definió rumbos de acción cuando comprobó que a los jóvenes los atrae significativamente el trabajo basado en opciones de memoria viva (talleres extraaula, visitas a museos y a sitios patrimoniales, aprendizaje por películas y documentales, diálogos directos con actores sociales, etc.), a diferencia del que ha sido paradójicamente el recurso más utilizado por los profesores: el texto escolar (p. 79). Se abre el camino 
para una categoría no contemplada en el estado del arte de Jiménez et al. (2012): la de proyectos de intervención en el aula regular, con una población aún más amplia de estudiantes que ni siquiera fueron víctimas directas, pero cuyo concurso se hace preciso para fortalecer a futuro los procesos de desarrollo de la memoria histórica. No en vano, González y Gárate aseveran:

Si los estudiantes estuvieran equipados con algunas herramientas intelectuales básicas del pensamiento histórico, provistas desde la clase de historia, estarian en condiciones de tener una visión global respecto de su presente y su horizonte futuro, $y$ asi poder desafiar todas aquellas interpretaciones del pasado colectivo que enmascaran viejas liturgias de sometimiento $y$ resignación. (2017, p. 84)

De este modo, la investigación basada en la recepción del estudiante, estimulada por la escucha a sus intereses, focalizada en la cristalización de cambios de actitud, centrada en estrategias metacognitivas, respetuosa de las diferencias y provocadora de procesos de argumentación razonada en torno a temas tan delicados como el respeto de los derechos humanos, los errores de la sociedad en el pasado y la esperanza de no repetir los períodos de violencia y de dictadura marcarían la agenda de las proyecciones de una escuela comprometida con la construcción de procesos de memoria histórica, tal como lo han conseguido en Chile Toledo y Magendzo (2013) y González y Gárate (2017).

\section{Desafios en cuanto al saber}

En lo que respecta al saber, nos adherimos a la observación de Magendzo y Toledo, en términos de que "el currículum escolar es un espacio en el que están en juego cuotas de poder que tienen diferentes agencias y agentes $y$, por lo tanto, es un acto político, además de técnico-pedagógico" (2009, p. 140). En virtud de ello, asoman nuevas posibilidades investigativas, a partir de las apuestas de Ri- vera y Mondaca que abogan por "espacios para la reflexión y el análisis de los hechos", con base en criterios de estructuración de contenidos como: la intersubjetividad, la actualización del discurso, el saber, el lenguaje, el contexto, el diálogo, el disenso frente a consenso, el aprendizaje social y colectivo, el sujeto alumno de la historia, entre otros (2013, pp. 398-399). La puesta en escena pedagógico-didáctica de estos y de otros nuevos criterios en el marco de proyectos de investigación-acción-participación jalonaría los estados del arte disponibles, pues haría posible imbricar uno de los mayores desafíos del saber histórico: su tejido temporal, pues cabe decir con González y Gárate:

Las tres dimensiones temporales (pasado, presente y futuro) se encuentran implícitas a la hora de pensar en qué cuestiones se concentran las clases de historia; en definitiva, se trata de: conocer el pasado, entender el presentey, en menor medida, hacerse la pregunta por el cambio histórico. Ciertamente, si pudiéramos avanzar en la comprensión de las nociones que los jóvenes elaboran en relación con el cambio, la orientación temporal o la identidad daríamos pasos fundamentales en la búsqueda de nuevos rumbos para la enseñanza de la historia. (2017, p. 83)

Viene bien decir que a los cambios de roles del maestro (ethos) y a la atención hacia el mundo del estudiante (pathos) debe sumarse la preocupación por el saber que se vehicula en el aula (logos) alrededor de un fenómeno tan lábil y poroso como la memoria histórica. De ahí que cualquier intento innovador de aula pueda mirar de soslayo las apuestas teóricas de un buen número de investigaciones en los tres países ${ }^{13}$.

13 Como las de González (2012), Adamoli et al. (2015) y Méndez (2017) en Argentina; o las de Magendzo y Toledo (2009), Rivera y Mondaca (2013), Moreno y Gamboa (2014), Rubio (2016), Mardones (2018) y Villalón y Zamorano (2018) en Chile; o las de Londoño y Carvajal (2015), Torres y Amaya (2015), Torres (2016), Padilla y Bermúdez (2016), Díaz y Rojas (2018) y González y García (2019) en Colombia; o la de Pagés y Marolla (2018). 


\section{A modo de conclusión}

Luego de procurar un acercamiento a las investigaciones recientes que auscultan los procesos de construcción de memoria histórica en Chile, Argentina y Colombia, desde el Estado, la sociedad civil y la escuela, podríamos sintetizar los siguientes hallazgos en cuanto a tendencias y desafíos.

Para las primeras, cada una de las tres instancias revisadas deja ver la presencia de ciertos patrones de convergencia. En cuanto al Estado, advertimos dos tendencias: una que podríamos denominar como cristalización de la memoria colectiva, en la cual se reflexiona acerca de la manera como el Estado reconoce su papel como uno de los actores de violencia; y otra que hemos llamado legislación y escuela, que recoge todo el dispositivo normativo de políticas educativas que concretan las primeras cristalizaciones de la memoria. En cuanto a la investigación desde la sociedad civil, observamos dos corrientes: una que puede recogerse a través de la metáfora/función del espacio para el luto y el resguardo de las memorias, y otra para la memoria como resistencia. Y en lo que respecta a la investigación desde la escuela, el corpus revisado nos deja ver tres puntos de confluencia: uno dirigido al papel del docente, otro hacia el impacto en los estudiantes y uno más acerca de la configuración del saber que se construye en el aula.

Para las prospectivas, en el marco del interés educativo de este artículo y en virtud de todo lo que resta por hacer en la escuela, los mismos tres puntos de confluencia hacia los cuales se dirigen las investigaciones determinan desafíos irrecusables. Para el caso del maestro, la investigación sobre memoria histórica tiene el reto de abordar su ethos, atendiendo tanto a la imposibilidad de definir actuaciones precisas como al rol de transformación y emancipación que debe suscitar en la clase; así, investigaciones sobre las creencias del maestro, las representaciones sociales que fluyen por sus interacciones o los criterios éticos y políticos que sustentan sus acciones de aula pueden estimular los desarrollos investigativos en torno al aún joven marco de discusión de las pedagogías y didácticas de la memoria. Para el caso del impacto en los estudiantes o universo del pathos, el reto investigativo despunta por el ámbito estratégico de las memorias vivas que incorporen al aula no solo los avances de la multimodalidad, sino también la interacción con escenarios y actores concretos que estimulen los procesos de construcción de memoria, más allá de los textos tradicionales sobre los que ha transitado buena parte de la atención docente. Y, por último, para el caso del saber enseñado o mundo del logos, el panorama escolar, si bien registra ostensibles avances fundados en los acuerdos epistemológicos sobre lo que debería enseñarse ${ }^{14}$, aún precisa de los múltiples aportes de experiencias de aula que muestren caminos praxeológicos sobre el proceder del maestro que gestiona el aprendizaje de sus estudiantes en torno al fenómeno lábil y poroso de la memoria histórica.

Ante este panorama tan retador y abierto a las posibilidades investigativas en el aula, quizás nos quede, en sintonía con Raggio, la esperanza de insinuar, al menos, la construcción de mejores futuros, si partimos del hecho de que recordar, así no garantice la no repetición, se constituye en utopía que implica "develar y asumir las condiciones que hicieron posible el pasado para reconocerlas en el presente" (2004, p. 14). Para el caso colombiano, las experiencias precursoras de Chile y Argentina, al igual que aquellas que ya se gestan en el propio territorio, marcan un derrotero interesante que encuentra en la consolidación de la memoria un motivo de cohesión y de empoderamiento que hace posible el avance hacia una sociedad distinta -al menos desde la utopía zuletiana- "capaz de tener mejores con-

14 Recordemos los trabajos de González (2012), Adamoli et al. (2015) y Méndez (2017) en Argentina; los de Magendzo y Toledo (2009), Rivera y Mondaca (2013), Moreno y Gamboa (2014), Rubio (2016), Mardones (2018) y Villalón y Zamorano (2018) en Chile; los de Londoño y Carvajal (2015), Torres y Amaya (2015), Torres (2016), Padilla y Bermúdez (2016), Díaz y Rojas (2018) y González y García (2019) en Colombia; o el de Pagés y Marolla (2018) en los tres países. 
flictos. De reconocerlos y de contenerlos. De vivir no a pesar de ellos, sino productiva e inteligentemente en ellos" (Zuleta, 1992, p. 67). Por una utopía de esta naturaleza, bien vale la pena apostar investigativamente desde los diversos polos del sistema didácti- co: desde la redefinición del ethos de quien enseña, desde la escucha al pathos de quien aprende y desde la relectura del logos de una memoria histórica tan oportuna como necesaria que en dichas interacciones se construye.

\section{Referencias}

Adamoli, M., Farías, M. y Flachsland, C. (2015). Educación y memoria. La historia de una política pública. Historia de la Educación, 16, 225-241. http://ppct.caicyt.gov.ar/index.php/anuario/article/view/8386

Arenas, S. (2015). Luciérnagas de la memoria. Altares espontáneos y narrativas de luto en Medellín, Colombia. Revista Interamericana de Bibliotecología, 38(3), 189-200. https://doi.org/10.17533/udea.rib.v38n3ao4

Bertola, C., Brarda, F., Bricca, D., Escudero, E., Vogler, M. (2015). Entre el pensar, el deciry el hacer... Representaciones de los docentes de ciencias sociales sobre el pasado reciente y su posibilidad didáctica en el segundo ciclo del nivel primario. Educación, Formación e Investigación, 1, 1-24. http://ppct.caicyt.gov.ar/index.php/efi/ article/view/6300/

Castrillón, J. E., Villa, J. D. y Marín, A. F. (2016). Acciones colectivas como prácticas de memoria realizadas por una organización de víctimas del conflicto armado en Medellín (Colombia). Revista Colombiana de Ciencias Sociales, 7(2), 404-424. https://doi.org/10.21500/16578031.3287

Caturelli,M. (2017). Formar parala democracia en el nivel primario. Aportes desdeuna experiencia en investigación. Educación, Formación e Investigación, 3(5), 173-180. http://dx.doi.org/10.4067/S0718-07051999000100006

Centro Nacional de Memoria Histórica (2018). Recorridos de la memoria histórica en la escuela: aportes de maestras y maestros en Colombia. CNMH. http://www.centrodememoriahistorica.gov.co/micrositios/ un-viaje-por-la-memoria-historica/pdf/recorridos-de-la-memoria-historica-en-la-escuela.pdf

Chevallard, Y. (1997). La transposición didáctica. Del saber sabio al saber enseñado. Aique.

Cisneros, M. y Olave, G. (2012). Redacción y publicación de artículos cientificos. Enfoque discursivo. Ecoe.

Crenzel, E. (2008). El relato canónico de las desapariciones en Argentina: El informe Nunca Más. Confines (agosto), 47-59. http://www.scielo.org.mx/pdf/confines/v4n8/v4n8a3.pdf

Comisión Nacional sobre la Desaparición de Personas (1984). Nunca Más. Informe de la Comisión Nacional sobre la Desaparición de Personas. Eudeba. http://www.derechoshumanos.net/lesahumanidad/informes/ argentina/informe-de-la-CONADEP-Nunca-mas-Indice.htm

Comisión Nacional de Verdad y Reconciliación (1991). Informe de la Comisión Nacional de Verdad y Reconciliación. DerechosHumanos.Net. [Portal web] http://www.derechoshumanos.net/lesahumanidad/informes/informe-rettig.htm 
Comisión Nacional sobre Prisión Política y Tortura (2004). Informe de la Comisión Nacional sobre Prisión Política y Tortura. Instituto Nacional de Derechos Humanos. [Portal web] https://bibliotecadigital.indh.cl/ handle/123456789/455

Cornejo, M., Reyes, M., Cruz, M., Villarroel, N., Vivanco, A., Cáceres, E. y Rocha, C. (2013). Historias de la dictadura militar chilena desde voces generacionales. Psykhe, 22(2), 49-65. https://doi.org/10.7764/psykhe.22.2.603

Cueto, S. (2010). Hijos de víctimas del terrorismo de Estado. Justicia, identidad y memoria en el movimiento de derechos humanos en Argentina, 1995-2008. Historia Crítica, 40, 122-145. http://www.memoria.fahce. unlp.edu.ar/art_revistas/pr.7384/pr.7384.pdf

Cueto, S. (2019). El origen de la Comisión Provincial por la Memoria de la provincia de Buenos Aires (Argentina, 1999-2000). Colombia Internacional, 97, 87-115. https://doi.org/10.7440/colombiaint97.2019.04

Díaz-Perdomo, M. y Rojas-Suárez, N. (2018). Educación para la ciudadanía en el posacuerdo. Eleuthera, 20, 13-34. http://www.scielo.org.co/pdf/eleut/v20/2011-4532-eleut-20-ooo13.pdf

Domínguez, J. y Feito-Alonso, R. (2007). Finalidades de la educación en una sociedad democrática. Octaedro.

Faletto, E. (1993). Política social, desarrollo y democracia en América Latina. Las funciones del Estado. Revista de Sociología, 8, 27-38. http://bibliotecavirtual.clacso.org.ar/ar/libros/coedicion/faletto/2.4.pdf

Figueroa, C. (2001). Dictaduras, tortura y terror en América Latina. Bajo el Volcán, 2(3), 53-74. http://www.redaly c. org/articulo.oa?id=28600304

Ghilarducci, D. (2018). Víctimas y memoria histórica. Las madres de Plaza de Mayo y el Movimiento de Víctimas de Crímenes de Estado en Colombia. Análisis Político, 93, 189-207. https://doi.org/10.15446/anpol. v31n93.75624

Gómez, M., Deslauriers, J. y Alzate, M. (2010). Cómo hacer tesis de maestría y doctorado. Ecoe.

González, F.y García, N. (2019). El arte y la literatura en la construcción de la memoria histórica: una experiencia de conmemoración en el Instituto Pedagógico Nacional. Pensamiento, Palabra y Obra, 21, 60-77. https:// doi.org/10.17227/ppo.num21-9462

González, M. (2011). Saberes y prácticas docentes en historia: usos y lecturas del nunca más. Revista Escuela de Historia, 10(2), 1-25. https://dialnet.unirioja.es/servlet/articulo?codigo $=5335390$

González, F.y Gárate, C. (2017). El aprendizaje histórico en la educación secundaria. Jóvenes chilenos y conciencia histórica. Diálogo Andino, 53, 73-85. http://dx.doi.org/10.4067/S0719-26812017000200073

González, M. (2012). Historia y memoria del pasado reciente en la escuela: una mirada a la propuesta oficial. Quinto Sol, 16(2), 1-24. http://www.biblioteca.unlpam.edu.ar/pubpdf/quisol/v16n2ao4gonzalez.pdf

Jiménez, A., Infante, R., Cortés, R. (2012). Escuela, memoria y conflicto en Colombia. Un ejercicio del estado del arte de la temática. Revista Colombiana de Educación, 62, 287-317. http://www.scielo.org.co/pdf/rcde/n62/ n62a15.pdf 
Larralde, F. (2014). Políticas de la memoria. A propósito de su vigésimo aniversario en la ciudad de La Plata (Argentina): la configuración de un campo y sus prácticas. Revista Mexicana de Ciencias Políticas y Sociales, 221, 267-29o. https://doi.org/10.1016/S0185-1918(14)70824-4

Londoño, J. y Carvajal, J. (2015). Pedagogías para la memoria histórica: reflexiones y consideraciones para un proceso de innovación en el aula. Ciudad Paz-Ando, 8(1), 124-141. http://dx.doi.org/10.14483/udistrital.jour. cpaz.2015.1.207

Magendzo, A. y Toledo, M. (2009). Educación en derechos humanos: currículum, historia y ciencias sociales del 2 año de enseñanza media. Subunidad régimen militar y transición a la democracia. Estudios Pedagógicos, 35(1), 139-154. https://doi.org/10.4067/S0718-07052009000100008

Mardones-Arévalo, R. (2018). Educación cívica y construcción de ciudadanía en el Chile de la posdictadura, ¿en qué estamos y para dónde vamos? Revista Austral de Ciencias Sociales, 35, 63-82. https://doi.org/10.4206/ rev.austral.cienc.soc.2018.n35-04

Méndez, L. (2017). Desandando pasados, tejiendo futuros. Las ciencias sociales escolares en perspectiva. KIMUN: Revista Interdisciplinaria de Formación Docente, 4, 124-137. http://ppct.caicyt.gov.ar/index.php/kimun/article/download/10772/9911

Meyer, M. (2013). Principia Rhetorica. Una teoría general de la argumentación. Amorrortu.

Montero, A. (2008). Justicia y decisión en el discurso presidencial argentino sobre la memoria (2003-2007). CONfines de Relaciones Internacionales y Ciencia Politica, 4(7), 27-41. https://www.felsemiotica.com/descargas/Montero-Ana-Soledad-Justicia-y-decisi\%C3\%B3n-en-el-discurso-presidencial-argentino-sobre-lamemoria-2003-2007.pdf

Moreno-Doña, A. y Gamboa, R. (2014). Dictadura chilena y sistema escolar: "a otros dieron de verdad esa cosa llamada educación". Educar em Revista, 51, 51-66. https://doi.org/10.1590/S0104-40602014000100005

Oteíza T.y Pinuer C. (2010). La temporalidad, recurso estratégico en documentos oficiales de derechos humanos en Chile. Estudios Filológicos, 46, 81-99. https://doi.org/10.4067/S0071-17132010000200005

Padilla, A. y Bermúdez, A. (2016). Normalizar el conflicto y desnormalizar la violencia: retos y posibilidades de la enseñanza crítica de la historia del conflicto armado colombiano. Revista Colombiana de Educación, 71, 219-251. http://www.scielo.org.co/pdf/rcde/n71/n71aog.pdf

Pagés, J. y Marolla, J. (2018). El papel de la memoria en la enseñanza de la historia en América. Historia y Memoria, 17, 153-184. https://doi.org/10.19053/20275137.n17.2018.7455

Pavón, D. y Sabucedo, J. (2009). El concepto de "sociedad civil": breve historia de su elaboración teórica. Araucaria. Revista Iberoamericana de Filosofía, Política y Humanidades, 11(21), 63-92. http://www.redaly c.org/ articulo.oa?id=28211600004

Perochena, C. (2020). Entre el “deber de memoria” y el uso político del olvido: México y Argentina frente al pasado reciente. Historia y Memoria, 20, 23-59. https://doi.org/10.19053/20275137.n20.2020.9560 
Rabotnikof, N. (2007). Memoria y política a 30 años del golpe. En Argentina, 1976, estudios en torno al golpe de estado (pp. 259-284). Fondo de Cultura Económica.

Raggio, S. (2004). La enseñanza del pasado reciente. Hacer memoria y escribir la historia en el aula. Revista Clío \& Asociados. La Historia Enseñada 5(8), 1-16. https://bibliotecavirtual.unl.edu.ar/publicaciones/index. php/ClioyAsociados/article/view/1594

Raina, A. (2018). Sobre la necesaria vinculación entre historia y memoria en el estudio de la historia reciente en Argentina. Reflexiones a partir de un análisis de caso. Estudios Politicos, 43, 163-19o. http://www.scielo.org. $\mathrm{mx} / \mathrm{pdf} / \mathrm{ep} / \mathrm{n} 43 / 0185-1616-\mathrm{ep}-43-163 . \mathrm{pdf}$

Rivera, P. y Mondaca, C. (2013). El aporte de la enseñanza de la historia reciente en Chile: Disensos y consensos desde la transición política al siglo XXI. Estudios Pedagógicos, 39(1),393-401. https://doi.org/10.4067/So71807052013000100023

Rubio, G. (2016). Memoria hegemónica y memoria social. Tensiones y desafíos pedagógicos en torno al pasado reciente en Chile. Revista Colombiana de Educación, 71, 109-135. http://www.scielo.org.co/pdf/rcde/n71/ n71a05.pdf

Rubio, G. y Osorio, J. (2017). Memoria, procesos identitarios y pedagogías: El caso chileno. Revista Latinoamericana de Educación Inclusiva, 11(1), 131-150. http://dx.doi.org/10.4067/S0718-73782017000100009

Sierra, T. y Medina, B. (2012). Convivencia escolar y Derechos Humanos como herramienta para la calidad educativa. Acercamiento conceptual IED Gabriel Betancourt Mejía. En Memoria, conflicto y escuela. Voces y experiencias de maestros y maestras en Bogotá (pp. 151-160). IDEP.

Toledo, M. y Magendzo, A. (2013). Golpe de Estado y dictadura militar: Estudio de un caso único de la enseñanza de un tema controversial en un sexto año básico de un colegio privado de la región metropolitana-Santiago, Chile. Psykhe, 22(2), 147-16o. http://dx.doi.org/10.7764/psykhe.22.2.585

Torres, D. (2020). Museo de Memoria Histórica de Colombia (2012-2019) ¿Un lugar para el diálogo memorial? Historia y Memoria, 20, 135-168. https:/doi.org/10.19053/20275137.n20.2020.9549

Torres, I. y Amaya, A. (2015). Construcciones y diálogos desde la enseñanza de la Historia Presente y las Pedagogías de la Memoria en el escenario colombiano. Revista do Corpo Discente do PGG-Histórica da UFRGS, 7(16), 382-403. https://seer.ufrgs.br/aedos/article/view/51008

Torres, L. (2016). Historia reciente en la escuela colombiana: acercamiento a las nociones de memoria, historia y conflicto. Revista Colombiana de Educación, 71, 165-185. https://doi.org/10.19053/20275137.n17.2018.7455

Traverso, E. (2007). El pasado, instrucciones para su uso. Historia, memoria, política. Marcial Pons.

Uprimny, C. (2011). La memoria en la Ley de Víctimas en Colombia: derecho y deber. Voces Ausentes: Memoria la Voz de las Víctimas. Universidad Santo Tomás. https://anuariocdh.uchile.cl/index.php/ADH/article/ download/20563/21733/ 
ISSN 0123-1294 | e-ISSN 2027-5358 | Educ.Educ. Vol. 23. No.3 | Agosto-octubre de 2020 | pp. 402-424

Universidad de La Sabana | Facultad de Educación

Villa, J. D. y Barrera, D. (2017). Registro identitario de la memoria: políticas de la memoria e identidad nacional. Revista Colombiana de Sociología, 40 (suplemento 1), 149-172. https://doi.org/10.15446/rcs.v40n1Supl.65911

Villalón, G.y Zamorano, A. (2018). Presencia y perspectivas de la enseñanza de la Historia reciente en la Historia enseñada en la educación secundaria en Chile. Un análisis desde el currículum. Revista Austral de Ciencias Sociales, 34, 139-151. https://doi.org/10.4206/rev.austral.cienc.soc.2018.n34-09

Zuleta, E. (1992). Ensayos selectos. Gobernación de Antioquia. 